\title{
Assessment of Ventricular Function in Adults with Sickle Cell Disease: Role of Two-Dimensional Speckle-Tracking Strain
}

\author{
Marcia M. Barbosa, MD, PhD, Maria Carmen M. Vasconcelos, MD, Teresa Cristina A. Ferrari, MD, PhD, \\ Bárbara Martins Fernandes, Luiz Guilherme Passaglia, MD, Célia Maria Silva, MD, PhD, \\ and Maria Carmo P. Nunes, MD, PhD, Belo Horizonte, Brazil
}

\begin{abstract}
Background: Sickle cell disease (SCD) is a hemoglobinopathy that is common worldwide. It usually presents with cardiac involvement, although data on systolic function are somewhat controversial. The aim of this study was to investigate the value of speckle-tracking strain, a deformation index, in detecting ventricular dysfunction in SCD.
\end{abstract}

Methods: Ninety adult patients with SCD were compared with 20 healthy controls. Doppler echocardiography with Doppler tissue imaging was performed in all, and the left and right ventricles were analyzed by the use of two-dimensional speckle-tracking strain.

Results: The mean age of the patients with SCD was 26 years, and $43 \%$ were men. Left ventricular (LV) dimensions and mass were higher in patients with SCD, whereas LV ejection fraction did not differ from the controls. $E$ and $A$ waves, as well as $E / e^{\prime}$ ratio, were also higher in patients with SCD. Two-dimensional speckle-tracking strain of both ventricles in the patients with SCD was not different from that of controls. The factors independently associated with LV longitudinal strain were age $(P=.009)$, oximetry $(P=.001)$, lactate dehydrogenase $(P=.014)$, LV ejection fraction $(P<.001)$, and right ventricular systolic annular velocity $(P=.010)$.

Conclusions: Ventricular enlargement with normal ventricular function was a frequent finding in SCD. Twodimensional speckle-tracking strain of both ventricles was similar in patients and controls, suggesting normal myocardial contractility in patients with SCD. LV global longitudinal strain was associated with age, intensity of hemolysis, and ventricular function. (J Am Soc Echocardiogr 2014;27:1216-22.)

Keywords: Sickle cell disease, Two-dimensional speckle-tracking strain, Ventricular function, Echocardiography

Sickle cell disease (SCD) is a frequent inherited hemoglobinopathy that affects approximately 100,000 individuals in the United States, with a prevalence of 1 in 365 African Americans. ${ }^{1}$ Cardiovascular complications are increasingly identified in patients with SCD and have been associated with mortality. ${ }^{2-6}$ Several mechanisms have been proposed to explain cardiac involvement in SCD, including chronic anemia, ${ }^{7,8}$ progressive dysplasia or thrombotic occlusion of coronary vessels, ${ }^{7}$ intrinsic cardiomyopathy, ${ }^{9}$ and pulmonary hypertension. ${ }^{10-12}$

Pulmonary hypertension represents a serious complication of SCD associated with increased morbidity and mortality. ${ }^{13-15}$ Both left ventricular (LV) systolic and diastolic dysfunction may occur in

From the Universidade Federal de Minas Gerais, Belo Horizonte, Brazil (M.M.B., M.C.M.V., T.C.A.F., B.M.F., L.G.P., M.C.P.N.); Ecocenter, Socor Hospital, Belo Horizonte, Brazil (M.M.B.); Fundação Centro de Hematologia e Hemoterapia de Minas Gerais (Hemominas Foundation), Belo Horizonte, Brazil (C.M.S.)

Reprint requests: Marcia M. Barbosa, MD, PhD, Conde do Rio Pardo, 288, 34000 000 Nova Lima, MG, Brazil (E-mail: marciambarbosa@terra.com.br).

0894-7317/\$36.00

Copyright 2014 by the American Society of Echocardiography.

http://dx.doi.org/10.1016/j.echo.2014.07.014

1216 adults and children with SCD, but LV systolic dysfunction is not common and is usually observed in older patients and in those with associated disorders such as systemic hypertension and renal failure. $^{13,16}$ Although most studies in adults show abnormalities of LV diastolic function, ${ }^{3,17-19}$ LV ejection fraction (LVEF) and/or other conventional indices of systolic function have usually been reported to remain normal. ${ }^{20}$ It is well known that conventional indices of LV systolic function are limited in identifying and measuring early ventricular dysfunction because of the volume-expanded highcardiac output state present in chronic anemia. Strain, a parameter that seems to be independent of ventricular geometry and, to a lesser extent, of ventricular loading conditions, ${ }^{21}$ has been used to detect incipient LV and right ventricular (RV) systolic dysfunction in several heart diseases. However, only a few studies, with small numbers of patients, have addressed the role of strain in detecting subclinical changes in ventricular function in SCD, and their results are somewhat controversial. ${ }^{22-24}$

Thus, the purpose of the present study was to use two-dimensional (2D) speckle-tracking strain to evaluate RV and LV function to determine if incipient ventricular systolic dysfunction in SCD can be detected, despite a normal LVEF. In addition, we investigated the associations between demographic, clinical, laboratory, and echocardiographic parameters and LV longitudinal strain. 


\section{Abbreviations}

HbSS = Hemoglobin S

$\mathbf{L A}=$ Left atrial

$\mathbf{L V}=$ Left ventricular

LVEF = Left ventricular ejection fraction

$\mathbf{R V}=$ Right ventricular

SCD $=$ Sickle cell disease

TRV $=$ Tricuspid regurgitation velocity

2D = Two-dimensional

\section{METHODS}

\section{Study Group}

Adult outpatients ranging from 18 to 40 years of age, homozygous for hemoglobin $\mathrm{S}(\mathrm{HbSS})$ or who had $S \beta^{0}$ thalassemia attended at Hemominas Foundation, a referral center for SCD in Belo Horizonte, Brazil, were included. Patients were prospectively enrolled if the diagnosis of SCD had been previously documented by hemoglobin electrophoresis on cellulose acetate and on acid citrate agar showing an absence of hemoglobin A and positive results for sickling. Individuals with $\mathrm{HbSS}$ and hemoglobin $S \beta^{0}$ were selected because they present a very similar clinical course. ${ }^{25,26}$ The control group consisted of patients without any histories of cardiac disease who were seen at the echocardiography laboratory and had normal results on Doppler echocardiography.

Patients outside the age range or who presented with associated conditions (hypertension, diabetes, alcohol or drug abuse, pregnancy, chronic obstructive lung disease, rheumatic heart disease, and other cardiomyopathies) were excluded.

The study was approved by the institutional research ethics com mittee of the Hemominas Foundation and Universidade Federal de Minas Gerais, and written informed consent was obtained from all patients.

\section{Clinical Evaluation}

At entry, a complete clinical evaluation and routine laboratory examinations were carried out on all patients. Only patients clinically stable for $\geq 4$ weeks were included, and functional status was determined using the New York Heart Association classification on the basis of functional capacity and dyspnea.

Electrocardiography and comprehensive Doppler echocardiography, with color flow mapping, tissue Doppler imaging, and speckletracking (2D strain) of both left and right ventricles, were also performed in all patients.

\section{Doppler Echocardiography}

Doppler echocardiography with color flow mapping was performed using a Vivid 7 system (GE Healthcare, Milwaukee, WI) with multifrequency transducers. M-mode measurements were performed according to the American Society of Echocardiography recommendations. ${ }^{27}$ LV mass was calculated using Devereux's formula. $^{28}$

LV diastolic function was assessed by pulsed Doppler of the mitral inflow and by tissue Doppler imaging measurements, obtained at the medial and lateral border of the mitral annulus in the apical fourchamber view. Systolic tissue Doppler velocity $\left(S^{\prime}\right)$ and early $\left(\mathrm{e}^{\prime}\right)$ and late $\left(\mathrm{A}^{\prime}\right)$ diastolic tissue velocities were acquired, and the ratio of the mitral $E$ velocity to the mean $e^{\prime}$ was calculated $\left(E / e^{\prime}\right)$. Measurements were averaged over three beats. ${ }^{29}$

Right atrial area was measured in end-systole in the apical fourchamber view. ${ }^{27} \mathrm{RV}$ areas at end-systole and end-diastole were obtained in the apical four-chamber view, and fractional area change was calculated as (RV end-diastolic area - RV end-systolic area)/RV end-diastolic area $\times 100$. RV tissue Doppler imaging was performed at the lateral tricuspid annulus in the apical four-chamber view, where peak systolic $\left(\mathrm{S}^{\prime}\right)$ and early $\left(\mathrm{e}^{\prime}\right)$ and late $\left(\mathrm{A}^{\prime}\right)$ diastolic velocities were measured.

The presence and severity of valvular regurgitation was evaluated by integrating several parameters, as recommended. ${ }^{30}$ Maximal tricuspid regurgitation velocity (TRv) was obtained in the fourchamber or parasternal view.

\section{RV and LV 2D Strain}

Images of the left ventricle in the apical four-, two-, and threechamber views were obtained for analysis, as previously described. ${ }^{21}$ The left ventricle was divided into 18 segments and, by using a dedicated software package (EchoPAC PC version 7.0.X; GE Healthcare, Fairfield, CT), 2D LV longitudinal strain was obtained for each segment. Longitudinal strain was assessed in all six LV walls in the three apical views, and the average value of each wall on each view was used for comparisons with the controls (Figure 1). RV longitudinal strain was also measured in a modified four-chamber view, aiming at the right ventricle and using the same software provided for the left ventricle (Figure 2). Both septal and free RV walls were measured and the mean value of the six segments was used to calculate RV global longitudinal strain. ${ }^{31}$

Radial and circumferential strain were assessed in the six LV walls in the parasternal LV short-axis view at the levels of the papillary muscles and mitral valve, and their average values were used for comparison with the controls. Global longitudinal, radial, and circumferential strains were obtained by dividing the sum of the strain from all LV walls segments by the number of segments.

\section{Statistical Analysis}

Categorical data are presented as numbers and percentages and continuous data as mean $\pm S D$ or median (interquartile range). The variables of patients with SCD and controls were compared using $\chi^{2}$ tests, unpaired Student's $t$ tests, or Mann-Whitney tests as appropriate. A multivariate linear regression model was performed to estimate the association between clinical, demographic, laboratory, and echocardiographic variables with LV global longitudinal strain. The reproducibility of three types of LV strain and RV strain was assessed by the intraclass correlation coefficients for repeated measures in a random sample of 15 patients. $P$ values $<.05$ were considered signif icant. SPSS version 18 (SPSS, Inc, Chicago, IL) was used for all analyses.

\section{RESULTS}

\section{Study Group}

A total of 106 patients with SCD who were referred to the Hemominas Foundation were initially considered for the study. On the basis of exclusion criteria, 16 patients $(15 \%)$ were not eligible for the study. A total of 90 adults with SCD, genotype HbSS (86 patients) or $S \beta^{0}$ thalassemia (four patients), ranging from 18 to 40 years of age, were included. The control group consisted of 20 age- and gender-balanced control patients. Their clinical and demographic characteristics, as well as Doppler echocardiographic data, are presented in Table 1.

Forty-two patients with SCD (47\%) were on hydroxyurea, and 16 individuals (18\%) with the genotype HbSS who had histories of stroke were under hypertransfusion (i.e., periodic transfusion at regularly 


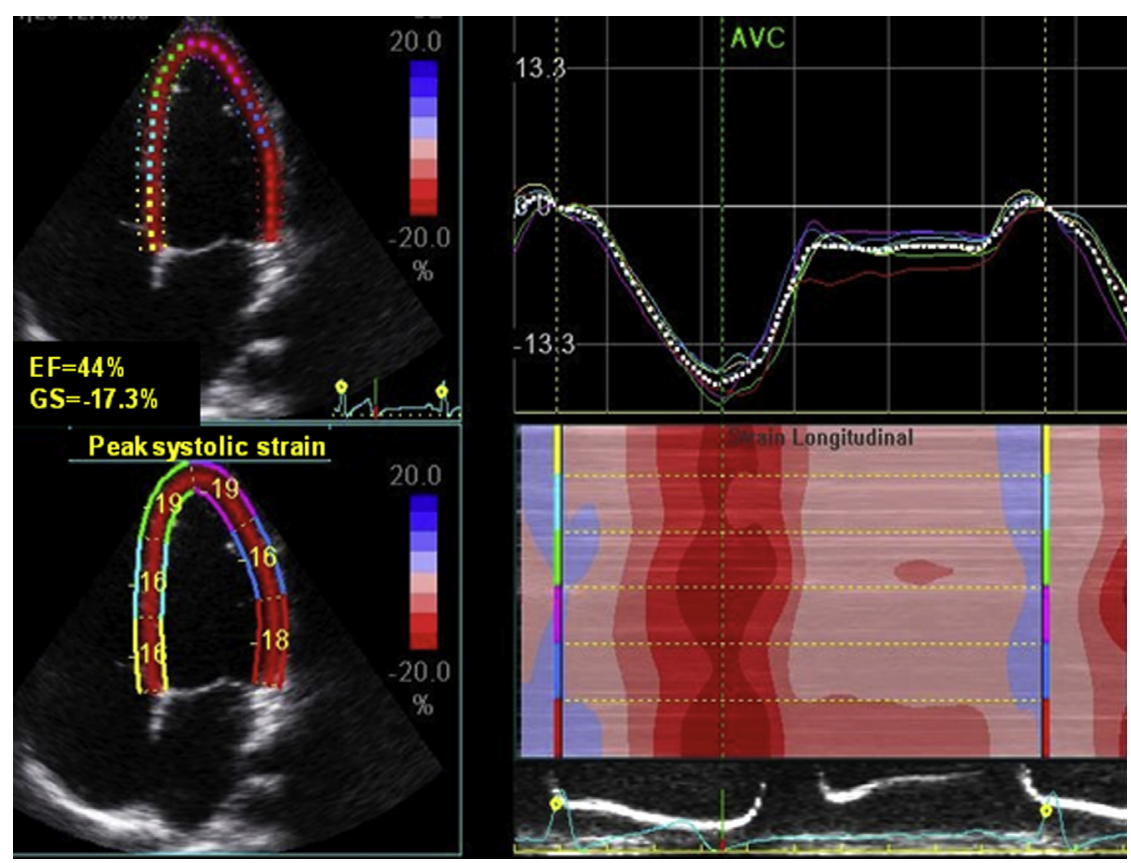

Figure 1 Two-dimensional longitudinal strain imaging showing segmental peak systolic longitudinal strain of the left ventricle in the apical four-chamber view.

scheduled intervals to maintain the percentage $\mathrm{HbSS}<30 \%$ of total hemoglobin). The patients on hydroxyurea or on hypertransfusion regimen had higher hemoglobin values $(9.5 \pm 1.7$ vs $8.2 \pm 1.2 \mathrm{~g} /$ $\mathrm{dL}, \quad P<.001)$, lower reticulocyte counts $(0.8 \pm 0.6 \%$ vs $1.4 \pm 0.5 \%, P<.01$ ), and better oxygen saturation (95\% vs. $92 \%$, $P=.010)$ than those not undergoing these treatment modalities. Body surface area was lower in the patients, while both blood pressure and heart rate were similar to those of the controls. LV dimensions and indexed mass were higher in patients with SCD, and LVEFs was equal in patients and controls (Table 1). Both septal and lateral mitral annular velocities were similar between patients with SCD and control subjects.

\section{Ventricular Function}

Mitral E and A waves were higher in patients with SCD, while septal and lateral $\mathrm{e}^{\prime}$ were similar to those of the controls. As a consequence, $\mathrm{E} / \mathrm{e}^{\prime}$ ratios were also higher in patients, but they still remained within the normal range. Left atrial (LA) diameter and indexed volume were higher in patients with SCD (Table 2).

Diastolic and systolic RV areas were both higher in patients with SCD, while RV fractional area change remained normal and similar to that of the controls (Table 3), as well as RV strain. The other conventional RV function indices were similar between the groups.

Because patients with primary heart valve disease were excluded, all patients had no or mild mitral regurgitation, and four patients had moderate tricuspid regurgitation. $\mathrm{RV} \mathrm{S}^{\prime}$ was higher in the patients than in the controls. In patients with SCD, maximal TRv ranged from 2.1 to $3.3 \mathrm{~m} / \mathrm{sec}$ and was $\geq 2.8 \mathrm{~m} / \mathrm{sec}$ in 10 of them (9\%), with only one patient presenting a $\mathrm{TRv}>3.0 \mathrm{~m} / \mathrm{sec}$

\section{Two-Dimensional Speckle-Tracking Strain}

The three modalities of LV strain did not differ between patients with SCD and controls, as shown in Table 2. RV longitudinal strain in pa- tients with SCD was also normal and similar to that in controls, even when the subgroup of patients with elevated pulmonary pressure was compared with the controls (Table 3).

In the multivariate linear regression analysis adjusted for age, blood pressures, body surface area, hydroxyurea treatment, oximetry laboratory markers of hemolysis, and echocardiographic variables including LA mass, LVEF, RV fractional area change, RV systolic annular velocity, $\mathrm{TRv}$, and $\mathrm{E} / \mathrm{e}^{\prime}$ ratio, the factors that remained independently associated with LV longitudinal strain were age $(P=.009)$, oximetry $(P=.001)$, lactate dehydrogenase $(P=.014)$, LVEF $(P<.001)$, and RV systolic annular velocity $(P=.010)$ (Table 4$)$.

\section{Reproducibility}

The intraclass correlation coefficients for LV global longitudinal, radial, and circumferential strain were $0.97,0.93$, and 0.59 , respectively, for interobserver, and 0.97, 0.96, and 0.75, respectively, for intraobserver variability. For RV global strain, the intraclass correlation coefficients were 0.92 for interobserver variability and 0.93 for intraobserver variability.

\section{DISCUSSION}

The present study showed no difference in LV and RV systolic function, evaluated by 2D speckle-tracking strain between adults with SCD and healthy controls. LV global longitudinal strain was associated with age, oximetry, intensity of hemolysis assessed by lactate de hydrogenase, and LV and RV systolic function.

\section{Left Chambers Structure and Function}

In our study, conventional Doppler echocardiographic parameters demonstrated increased LV and LA diameters, as well as LV mass, similar to what has been extensively shown in both adults ${ }^{3,16,32}$ and children. ${ }^{18}$ Larger left and right chambers in individuals with SCD 

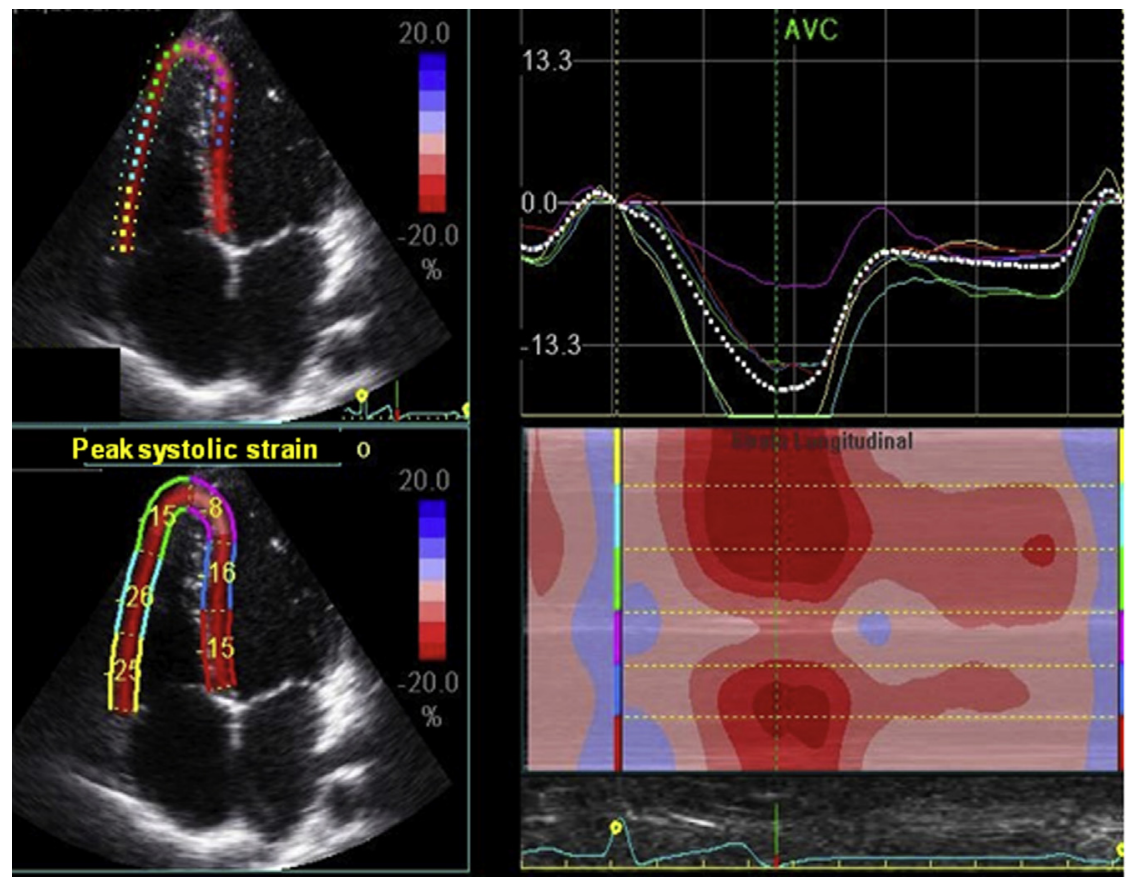

Figure 2 Two-dimensional longitudinal strain imaging of the right ventricle in the apical four-chamber view.

Table 1 Clinical and LV echocardiographic data in patients with SCD compared with controls

\begin{tabular}{lccr}
\hline \multicolumn{1}{c}{ Variable } & Patients & Controls & $P$ \\
\hline Age $(\mathrm{yrs})$ & $26.5(22-33)$ & $27.5(24-35)$ & .162 \\
Men & $39(43 \%)$ & $9(45 \%)$ & .542 \\
BSA $\left(\mathrm{m}^{2}\right)$ & $1.6 \pm 0.2$ & $1.8 \pm 0.2$ & .017 \\
Heart rate (beats/min) & $72(63-78)$ & $65(60-70)$ & .122 \\
Systolic pressure $(\mathrm{mm} \mathrm{Hg})$ & $110(105-120)$ & $110(110-120)$ & .680 \\
Diastolic pressure $(\mathrm{mm} \mathrm{Hg})$ & $70(60-80)$ & $70(70-80)$ & .166 \\
LVEDd $(\mathrm{mm})$ & $52(49-57)$ & $46(41-49)$ & $<.001$ \\
LVEDd/BSA $(\mathrm{mm})$ & $33(30-36)$ & $26(24-28)$ & $<.001$ \\
LVESd $(\mathrm{mm})$ & $34(31-37)$ & $30(26-32)$ & $<.001$ \\
LVEF $(\%)$ & $63(59-66)$ & $63(60-65)$ & .928 \\
VS $(\mathrm{mm})$ & $11(10-12)$ & $9.5(8-10)$ & $<.001$ \\
PW $(\mathrm{mm})$ & $11(10-12)$ & $9(8-10)$ & $<.001$ \\
Indexed LV mass $\left(\mathrm{g} / \mathrm{m}^{2}\right)$ & $147.9 \pm 42.7$ & $79.9 \pm 17.8$ & $<.001$ \\
\hline
\end{tabular}

$B S A$, Body surface area; LVEDd, LV end-diastolic diameter; $L V E S d$, LV end-systolic diameter; $P W$, posterior wall; VS, ventricular septum. Data are expressed as mean $\pm S D$, as median (interquartile range), or as number (percentage) of patients.

are probably an adaptive response to the increased stroke volume present in $\mathrm{SCD}^{20}$ that can gradually cause ventricular enlargement. Although the mechanism of heart failure in anemia is not completely understood, some factors have been reported to contribute to highoutput heart failure, including activation of the renin-angiotensinaldosterone system and hyperactivity of the sympathetic nervous system. However, these conditions are rarely the sole cause of heart failure; in most such patients, the high cardiac output provokes heart failure in the setting of reduced ventricular reserve from some underlying cardiac disorder. 32,33
Table 2 Doppler echocardiographic diastolic parameters in patients with SCD compared with controls

\begin{tabular}{|c|c|c|c|}
\hline Variable & Patients & Controls & $P$ \\
\hline $\mathrm{E}(\mathrm{cm} / \mathrm{sec})$ & $109.4 \pm 20.8$ & $89.1 \pm 14.0$ & $<.001$ \\
\hline $\mathrm{A}(\mathrm{cm} / \mathrm{sec})$ & $60.8 \pm 15.3$ & $49.6 \pm 9.7$ & .002 \\
\hline DT $(\mathrm{cm} / \mathrm{sec})$ & $224.0 \pm 37.9$ & $236.9 \pm 43.0$ & .186 \\
\hline IVRT (msec) & $75.2 \pm 9.5$ & $76.2 \pm 9.5$ & .656 \\
\hline$E / A$ & $1.9 \pm 0.5$ & $1.9 \pm 0.5$ & .872 \\
\hline Septal e' $(\mathrm{cm} / \mathrm{sec})$ & $12.3 \pm 2.2$ & $12.7 \pm 2.1$ & .452 \\
\hline Lateral $\mathrm{e}^{\prime}(\mathrm{cm} / \mathrm{sec})$ & $16.8 \pm 2.7$ & $16.3 \pm 2.6$ & .374 \\
\hline $\mathrm{E} / \mathrm{e}-$ ratio & $5.4 \pm 1.3$ & $4.3 \pm 0.7$ & $<.001$ \\
\hline LAd (mm) & $38(36-44)$ & $32(30-36.5)$ & $<.001$ \\
\hline LA volume index $\left(\mathrm{mL} / \mathrm{m}^{2}\right)$ & $35.8 \pm 12.1$ & $18.7 \pm 5.2$ & $<.001$ \\
\hline LV longitudinal strain (\%) & $-19.4 \pm 2.2$ & $-18.9 \pm 2.0$ & .377 \\
\hline LV radial strain (\%) & $35.5 \pm 11.1$ & $38.2 \pm 13.8$ & .427 \\
\hline LV circumferential strain (\%) & $-18.4 \pm 4.0$ & $-18.1 \pm 2.4$ & .772 \\
\hline
\end{tabular}

$D T$, Deceleration time of the $\mathrm{E}$ wave of the mitral valve; IVRT, isovolumic relaxation time; $L A d, L A$ diameter.

Data are expressed as mean \pm SD or as median (interquartile range).

Available data evaluating strain in the assessment of ventricular function in patients with SCD are limited. In the present study, no incipient LV systolic dysfunction was detected, and in both patients and controls, strain was within the normal limits, which is in agreement with a recently published meta-analysis. ${ }^{34}$ This finding is also similar to what was observed by Sengupta et al. ${ }^{23}$ who showed, in a study with a much smaller number of patients, no difference in LV strain between patients with SCD and controls.

The hyperdynamic state due to the volume overload present in SCD may mask incipient LV dysfunction. Strain might potentially be influenced by patient (age, gender, ethnicity, anthropometria), 
Table 3 RV measurements in patients with SCD compared with controls

\begin{tabular}{lccr}
\hline \multicolumn{1}{c}{ Variable } & Patients & Controls & \multicolumn{1}{c}{$P$} \\
\hline RV end-diastolic area $\left(\mathrm{cm}^{2}\right)$ & $14.1 \pm 3.5$ & $11.2 \pm 3.2$ & $<.001$ \\
RV end-systolic area $\left(\mathrm{cm}^{2}\right)$ & $7.9 \pm 2.1$ & $6.1 \pm 2.0$ & .001 \\
RV FAC $(\%)$ & $44.2 \pm 10.2$ & $45.1 \pm 8.6$ & .722 \\
Maximal TRv (m/sec) & $2.51 \pm 0.23$ & $2.15 \pm 0.21$ & $<.001$ \\
\hline TAPSE (mm) & $23.7 \pm 3.8$ & $22.9 \pm 2.0$ & .286 \\
RV e' (cm/sec) & $15.9 \pm 3.0$ & $14.7 \pm 3.0$ & .096 \\
RV A $(\mathrm{cm} / \mathrm{sec})$ & $12.2 \pm 3.3$ & $12.3 \pm 3.6$ & .954 \\
RV S (cm/sec) & $15.8 \pm 2.8$ & $14.2 \pm 2.3$ & .024 \\
RV e'/A ratio & $1.4 \pm 0.4$ & $1.3 \pm 0.4$ & .271 \\
RV global longitudinal & $21.6 \pm 3.1$ & $22.0 \pm 4.1$ & .679 \\
strain (\%) & & & \\
\hline
\end{tabular}

FAC, Fractional area change; TAPSE, tricuspid annular plane systolic excursion.

Data are expressed as mean \pm SD.

*Measured in 79 patients with SCD (88\%).

Table 4 Multivariate analysis of the factors associated with LV global longitudinal strain

\begin{tabular}{lcc}
\hline \multicolumn{1}{c}{ Variable } & $\beta$ & \multicolumn{1}{c}{$P$} \\
\hline Age & 0.104 & .009 \\
Oximetry & -0.191 & .001 \\
Lactate dehydrogenase & -0.001 & .014 \\
RV systolic annular velocity & 0.218 & .010 \\
LV ejection fraction & 0.254 & $<.001$ \\
\hline
\end{tabular}

The $R^{2}$ value for the final multivariate model was 0.53 .

hemodynamic (heart rate, blood pressure), and cardiac (ventricular size and wall thickness) factors. ${ }^{35}$ Deformation is related not only to contractility but also to ventricular size and geometry (Hooke's law). Detecting subclinical dysfunction in a volume overloaded ventricle may require the correction of the deformation parameters for LV volume and loading conditions ${ }^{36}$; however, current guidelines do not establish the necessity of adjusting speckle-tracking strain for gender or LV morphology. ${ }^{36}$ Strain increases with increased preload and decreases with increased afterload. ${ }^{21}$ Thus, the high preload present in patients with SCD may have masked the detection of incipient ventricular dysfunction by strain in this group of patients. In fact, in another study, in which 28 patients with SCD underwent three-dimensional strain assessment, ${ }^{24}$ even higher LV longitudinal strain was found in the patients compared with the controls. The authors suggested that this finding could be due to a cardiovascular system compensatory mechanism to keep adequate oxygenation in anemic patients.

Transfusion-related excessive iron stores is a cause of significant morbidity in patients with hemolytic anemia who receive frequent blood transfusions, and myocardial hemochromatosis is another factor that can affect strain. However, patients with SCD accumulate cardiac iron at a lower rate than patients with thalassemia major, which is frequently associated with myocardial iron deposition and iron-mediated cardiomyopathy. ${ }^{37}$ Moreover, in our study, an iron chelator was prescribed to the patients at risk for hemosiderosis to minimize iron deposition in organs such as the liver and the heart. ${ }^{38}$ Although a few patients with $S-\beta^{0}$ thalassemia were included in our investigation, this fact did not influence our results, as the clinical course of $S-\beta^{0}$ thalassemia is identical to that of SCD, which is different from the course of $\beta$-thalassemia major. ${ }^{25}$

Furthermore, $47 \%$ of our patients were on hydroxyurea, which is known to improve the overall course of the disease, decreasing hemolysis and its consequences. ${ }^{37}$ Therefore, the use of hydroxyurea and hypertransfusion in a subset of the patients with SCD could be another factor preventing the development of ventricular dysfunction and consequent detection of abnormal strain in these patients. However, LV and RV 2D strain were similar among patients on hydroxyurea and/or hypertransfusion and patients without treatment and controls.

Both the $\mathrm{E}$ and A waves were higher in patients with SCD, which is probably a result of increased preload. LA and indexed LA volume were significantly higher in patients with SCD, probably reflecting increased preload but also indicating some degree of diastolic dysfunction. Higher $\mathrm{E} / \mathrm{e}^{\prime}$ ratios were observed in patients with SCD. However, $\mathrm{E} / \mathrm{e}^{\prime}$ ratios remained within the normal range, suggesting that these patients, although presenting higher $\mathrm{E} / \mathrm{e}^{\prime}$ ratios, do not have elevated filling pressures. ${ }^{29}$ Our results support the observations that LV enlargement can occur, but with normal LV filling pressures and without overt heart failure.

\section{RV Function and Pulmonary Pressure in SCD}

RV adaptation to disease is complex and depends on many factors. There are some possible explanations for RV dysfunction in SCD, including LV diastolic dysfunction ${ }^{3,39}$ and elevation of pulmonary pressure due to increased cardiac output, rather than to increased pulmonary vascular resistance. ${ }^{22,32,40}$ Airway hyperactivity and sleep-disordered breathing have also been mentioned as etiologic factors. $^{3,41}$ In the present study, no RV dysfunction was detected using conventional echocardiographic methods, including M-modederived tricuspid annular motion, RV fractional area change, and tissue Doppler imaging, and speckle-tracking strain for additional information beyond standard measurements.

A previous study from Blanc et al. ${ }^{22}$ including 28 children with SCD showed lower RV longitudinal strain in the patients compared with the controls. However, global RV longitudinal strain was still within the normal range in the individuals with SCD. Global RV longitudinal strain was higher in that study than in ours $(28.5 \pm 5.6$ vs $21.6 \pm 3.1$, respectively), which may be related to the ages of the populations included in the studies. Additionally, other conventional RV function indices were similar between patients and controls, which are in agreement with our findings.

Similarly to what has been previously proposed, ${ }^{32}$ patients with SCD without pulmonary hypertension showed dilated right heart chambers without RV dysfunction. Furthermore, increased RV preload due to anemia may have prevented the detection of lower 2D strain, masking the identification of any incipient RV dysfunction that could be present. The fact that RV systolic annular velocity was higher in the patients with SCD than in the controls corroborates this hypothesis. Akgul et al., ${ }^{42}$ studying 48 young adults with SCD, also found higher RV systolic annular velocity values in patients with SCD than in controls. In contrast, Knight-Perry et al. ${ }^{32}$ found lower RV systolic annular velocity in patients with SCD compared with controls. A higher $S^{\prime}$ wave may be an expression of the relative "hyperdynamic" response of the right ventricle to the increased preload due to anemia.

In the setting of SCD, recent studies have shown that the prevalence of pulmonary hypertension is not as high as previously thought. A previous study showed that among subjects with SCD, pulmonary 
hypertension assessed by echocardiography (TRv $\geq 2.5 \mathrm{~m} / \mathrm{sec}$ ) was present in $40 \%$ of them. ${ }^{32}$ However, pulmonary hypertension confirmed by right-heart catheterization and defined as a mean pulmonary artery pressure $\geq 25 \mathrm{~mm} \mathrm{Hg}$ occurred in $6.2 \%{ }^{12}$ to $10 \%{ }^{10}$ of patients with SCD. In our study, only one patient had tricuspid regurgitation maximum velocity $>3.0 \mathrm{~m} / \mathrm{sec}$. Therefore, we believe that RV function in patients with SCD is determined mainly by ventricular afterload. This is corroborated by the fact that during acute chest syndrome, pulmonary pressures increase, leading to RV dysfunction. In a series of 84 consecutive hospital admissions, cor pulmonale was seen in $13 \%$ of patients with SCD during acute chest syndrome, and all these patients had TRv $\geq 3 \mathrm{~m} / \mathrm{sec}$ during the acute event. ${ }^{43}$

The present study of patients with SCD in steady state without pulmonary hypertension is in agreement with previous studies that have shown dilated right heart chambers without significant RV dysfunction. RV global strain in SCD being similar to controls supports the fact that strain decreases with increased afterload but appears not to be significantly affected by the high flow state of anemia.

\section{Limitations}

Because there is no specific software for the analysis of 2D RV strain, the longitudinal strain in this chamber was assessed by the use of LV software.

Assessment of RV function using 2D speckle-tracking longitudinal deformation strain is rapidly evolving in the investigational field. However, several factors should be considered before implementing this method in the clinical setting. Compared with the left ventricle, $\mathrm{RV}$ strain is more difficult to measure and to interpret. We measured global RV strain including the free wall and the septum, because septal contraction contributes to both RV and LV function. However, currently, there is no consensus on the best approach to assess RV strain. Inclusion of interventricular septal strain as a component of global RV strain varies among prior studies. ${ }^{44-47}$ Despite the limitations, previous studies have shown that 2D speckle-tracking strain permits the accurate assessment of RV function in many conditions, especially pulmonary hypertension. ${ }^{46,47}$

Although strain is considered relatively load independent, systolic strain is largely an ejection phase index, which is substantially dependent on preload and afterload. The impact of loading conditions and ventricular contractile state on strain parameters remains unclear. Advances in LV image-based evaluation in different loading conditions will permit meaningful assessment contractility using strain.

Our findings were obtained from a relatively young adult population and may not apply to an older population of patients with SCD. Another limitation is related to the fact that the patients were not submitted to right-heart catheterization for a more accurate measurement of pulmonary pressure.

\section{CONCLUSIONS}

Adults with SCD presented with ventricular enlargement but normal 2D speckle-tracking strain of both ventricles, reflecting normal myocardial function. LV global longitudinal strain was associated with age, oximetry, intensity of hemolysis, and LV and RV systolic function.

\section{REFERENCES}

1. Hassell KL. Population estimates of sickle cell disease in the U.S. Am J Prev Med 2010;38(4 Suppl):S512-21.
2. Mehari A, Gladwin MT, Tian X, Machado RF, Kato GJ. Mortality in adults with sickle cell disease and pulmonary hypertension. JAMA 2012;307: 1254-6.

3. Sachdev V, Machado RF, Shizukuda Y, Rao YN, Sidenko S, Ernst I, et al Diastolic dysfunction is an independent risk factor for death in patients with sickle cell disease. J Am Coll Cardiol 2007;49:472-9.

4. Eddine AC, Alvarez O, Lipshultz SE, Kardon R, Arheart K, Swaminathan S Ventricular structure and function in children with sickle cell disease using conventional and tissue Doppler echocardiography. Am J Cardiol 2012; 109:1358-64.

5. Lamers L, Ensing G, Pignatelli R, Goldberg C, Bezold L, Ayres N, et al. Evaluation of left ventricular systolic function in pediatric sickle cell anemia patients using the end-systolic wall stress-velocity of circumferential fiber shortening relationship. J Am Coll Cardiol 2006;47:2283-8.

6. Gladwin MT, Vichinsky E. Pulmonary complications of sickle cell disease. N Engl J Med 2008;359:2254-65.

7. Varat MA, Adolph RJ, Fowler NO. Cardiovascular effects of anemia. Am Heart J 1972;83:415-26.

8. Lester LA, Sodt PC, Hutcheon N, Arcilla RA. Cardiac abnormalities in children with sickle cell anemia. Chest 1990;98:1169-74.

9. Fleischer RA, Rubler S. Primary cardiomyopathy in nonanemic patients. Association with sickle cell trait. Am J Cardiol 1968;22:532-7.

10. Fonseca GH, Souza R, Salemi VM, Jardim CV, Gualandro SF. Pulmonary hypertension diagnosed by right heart catheterisation in sickle cell disease. Eur Respir J 2012;39:112-8.

11. Gerry JL, Baird MG, Fortuin NJ. Evaluation of left ventricular function in patients with sickle cell anemia. Am J Med 1976;60:968-72.

12. Parent F, Bachir D, Inamo J, Lionnet F, Driss F, Loko G, et al. A hemodynamic study of pulmonary hypertension in sickle cell disease. N Engl J Med 2011;365:44-53.

13. Gladwin MT, Sachdev V, Jison ML, Shizukuda Y, Plehn JF, Minter K, et al. Pulmonary hypertension as a risk factor for death in patients with sickle cell disease. N Engl J Med 2004;350:886-95.

14. Machado RF, Gladwin MT. Pulmonary hypertension in hemolytic disorders: pulmonary vascular disease: the global perspective. Chest 2010 137(6 Suppl):30S-8.

15. Miller AC, Gladwin MT. Pulmonary complications of sickle cell disease Am J Respir Crit Care Med 2012;185:1154-65.

16. Naoman SG, Nouraie M, Castro OL, Nwokolo C, Fadojutimi-Akinsiku M, Diaz $\mathrm{S}$, et al. Echocardiographic findings in patients with sickle cell disease. Ann Hematol 2010;89:61-6.

17. Kato G), Sachdev V. Diastolic dysfunction in sickle cell. Blood 2010;116:1-2.

18. Caldas MC, Meira ZA, Barbosa MM. Evaluation of 107 patients with sickle cell anemia through tissue Doppler and myocardial performance index. J Am Soc Echocardiogr 2008;21:1163-7.

19. Hankins JS, McCarville MB, Hillenbrand CM, Loeffler RB, Ware RE, Song R, et al. Ventricular diastolic dysfunction in sickle cell anemia is common but not associated with myocardial iron deposition. Pediatr Blood Cancer 2010;55:495-500.

20. Gladwin MT, Sachdev V. Cardiovascular abnormalities in sickle cell disease. J Am Coll Cardiol 2012;59:1123-33.

21. Marwick TH. Measurement of strain and strain rate by echocardiography ready for prime time? J Am Coll Cardiol 2006;47:1313-27.

22. Blanc J, Stos B, de Montalembert M, Bonnet D, Boudjemline Y. Right ventricular systolic strain is altered in children with sickle cell disease. J Am Soc Echocardiogr 2012;25:511-7.

23. Sengupta SP, Jaju R, Nugurwar A, Caracciolo G, Sengupta PP. Left ventricular myocardial performance assessed by 2-dimensional speckle tracking echocardiography in patients with sickle cell crisis. Indian Heart J 2012;64 553-8.

24. Ahmad H, Gayat E, Yodwut C, Abduch MC, Patel AR, Weinert L, et al Evaluation of myocardial deformation in patients with sickle cell disease and preserved ejection fraction using three-dimensional speckle tracking echocardiography. Echocardiography 2012;29:962-9.

25. Platt OS, Thorington BD, Brambilla DJ, Milner PF, Rosse WF, Vichinsky E, et al. Pain in sickle cell disease. Rates and risk factors. N Engl J Med 1991 325:11-6. 
26. Castro O, Brambilla DI, Thorington B, Reindorf CA, Scott RB, Gillette P, et al. The acute chest syndrome in sickle cell disease: incidence and risk factors. The Cooperative Study of Sickle Cell Disease. Blood 1994;84: 643-9.

27. Lang RM, Bierig M, Devereux RB, Flachskampf FA, Foster E, Pellikka PA, et al. Recommendations for chamber quantification: a report from the American Society of Echocardiography's Guidelines and Standards Committee and the Chamber Quantification Writing Group, developed in conjunction with the European Association of Echocardiography, a branch of the European Society of Cardiology. J Am Soc Echocardiogr 2005; 18 1440-63.

28. Devereux RB, Reichek N. Echocardiographic determination of left ventricular mass in man. Anatomic validation of the method. Circulation 1977; 55:613-8.

29. Nagueh SF, Appleton CP, Gillebert TC, Marino PN, Oh JK, Smiseth OA, et al. Recommendations for the evaluation of left ventricular diastolic function by echocardiography. J Am Soc Echocardiogr 2009;22:107-33.

30. Zoghbi WA, Enriquez-Sarano M, Foster E, Grayburn PA, Kraft CD Levine RA, et al. Recommendations for evaluation of the severity of native valvular regurgitation with two-dimensional and Doppler echocardiography. J Am Soc Echocardiogr 2003;16:777-802.

31. Horton KD, Meece RW, Hill JC. Assessment of the right ventricle by echocardiography: a primer for cardiac sonographers. J Am Soc Echocardiogr 2009;22:776-92. quiz 861-2.

32. Knight-Perry JE, de Las Fuentes L, Waggoner AD, Hoffmann RG, Blinder MA, Davila-Roman VG, et al. Abnormalities in cardiac structure and function in adults with sickle cell disease are not associated with pulmonary hypertension. J Am Soc Echocardiogr 2011;24:1285-90.

33. Dham N, Ensing G, Minniti C, Campbell A, Arteta M, Rana S, et al. Prospective echocardiography assessment of pulmonary hypertension and its potential etiologies in children with sickle cell disease. Am J Cardiol 2009; 104:713-20.

34. Yingchoncharoen T, Agarwal S, Popovic ZB, Marwick TH. Normal ranges of left ventricular strain: a meta-analysis. J Am Soc Echocardiogr 2013;26: 185-91.

35. Marwick TH, Leano RL, Brown J, Sun JP, Hoffmann R, Lysyansky P, et al. Myocardial strain measurement with 2-dimensional speckle-tracking echocardiography: definition of normal range. JACC Cardiovasc Imaging 2009;2:80-4
36. Blessberger $\mathrm{H}$, Binder T. NON-invasive imaging: Two dimensional speckle tracking echocardiography: basic principles. Heart 2010;96:716-22.

37. Kremastinos DT, Farmakis D, Aessopos A, Hahalis G, Hamodraka E, Tsiapras D, et al. Beta-thalassemia cardiomyopathy: history, present considerations, and future perspectives. Circ Heart Fail 2010;3:451-8.

38. Brittenham GM. Iron-chelating therapy for transfusional iron overload. N Engl I Med 2011;364:146-56.

39. Zilberman MV, Du W, Das S, Sarnaik SA. Evaluation of left ventricular diastolic function in pediatric sickle cell disease patients. Am J Hematol 2007; 82:433-8.

40. Caughey MC, Hinderliter AL, Jones SK, Shah SP, Ataga KI. Hemodynamic characteristics and predictors of pulmonary hypertension in patients with sickle cell disease. Am J Cardiol 2012;109:1353-7.

41. Johnson MC, Kirkham FJ, Redline S, Rosen CL, Yan Y, Roberts I, et al. Left ventricular hypertrophy and diastolic dysfunction in children with sickle cel disease are related to asleep and waking oxygen desaturation. Blood 2010, 116:16-21.

42. Akgul F, Yalcin F, Babayigit C, Seyfeli E, Seydaliyeva T, Gali E. Right ventricular and pulmonary function in sickle cell disease patients with pulmonary hypertension. Pediatr Cardiol 2006;27:440-6.

43. Mekontso Dessap A, Leon R, Habibi A, Nzouakou R, Roudot-Thoraval F, Adnot $\mathrm{S}$, et al. Pulmonary hypertension and cor pulmonale during severe acute chest syndrome in sickle cell disease. Am J Respir Crit Care Med 2008; 177:646-53.

44. Meris A, Faletra F, Conca C, Klersy C, Regoli F, Klimusina J, et al. Timing and magnitude of regional right ventricular function: a speckle trackingderived strain study of normal subjects and patients with right ventricular dysfunction. J Am Soc Echocardiogr 2010;23:823-31.

45. Puwanant S, Park M, Popovic ZB, Tang WH, Farha S, George D, et al. Ventricular geometry, strain, and rotational mechanics in pulmonary hypertension. Circulation 2010;121:259-66.

46. Fine NM, Chen L, Bastiansen PM, Frantz RP, Pellikka PA, Oh JK, et al Outcome prediction by quantitative right ventricular function assessment in 575 subjects evaluated for pulmonary hypertension. Circ Cardiovasc Imaging 2013;6:711-21.

47. Utsunomiya H, Nakatani S, Okada T, Kanzaki H, Kyotani S, Nakanishi N et al. A simple method to predict impaired right ventricular performance and disease severity in chronic pulmonary hypertension using strain rate imaging. Int J Cardiol 2011;147:88-94. 